\title{
ZnO nanorods/graphene oxide sheets prepared by chemical bath deposition for volatile organic compounds detection
}

\author{
Beatriz A. Vessalli a , Cecilia A. Zito ${ }^{\mathrm{b}}$, Tarcísio M. Perfecto ${ }^{\mathrm{b}}$, Diogo P. Volanti ${ }^{\mathrm{b}}{ }^{*}$, \\ Talita Mazon ${ }^{\mathrm{a}}$ \\ a Center for Information Technology Renato Archer, CTI, Rod. D. Pedro I, KM 143.6, 13069-901, Campinas, SP, Brazil \\ b LabMatSus - Laboratory of Materials for Sustainability, IBILCE, UNESP - Univ Estadual Paulista, Rua Cristóvão Colombo, 2265, S. J. Rio Preto, 15054-000, \\ Brazil
}

\section{A R T I C L E I N F O}

\section{Article history:}

Received 29 August 2016

Received in revised form

26 November 2016

Accepted 5 December 2016

Available online 8 December 2016

\section{Keywords:}

Nanocomposites

Sensors

Acetone

Zinc oxide

\begin{abstract}
A B S T R A C T
Graphene-based composites have emerged as gas sensor due to the possibility to obtain higher surface area with additional functional groups. In this paper, $\mathrm{ZnO}$ nanorods ( $\mathrm{ZnO}-\mathrm{NR}$ ) with controlled size and morphology were grown via chemical bath deposition in mild temperature $\left(90^{\circ} \mathrm{C}\right)$ over gold interdigital tracks deposited on an alumina substrate. Furthermore, it was also possible to obtain by the same method composites with graphene oxide sheets below $\mathrm{ZnO}-\mathrm{NR}$ structures (GO/ZnO-NR) or ZnO-NR between $\mathrm{GO}$ sheets (GO/ZnO-NR/GO) when GO is placed in the bath during the growth of GO/ZnO-NR. The samples were characterized by Raman spectroscopy, scanning electron microscopy, and energy dispersive X-ray spectroscopy. These structures were tested as sensors of volatile organic compounds (VOCs), such as acetone, benzene, ethanol and methanol in the concentration range of 10-500 parts per million (ppm). It was found that the optimum working temperature of all sensors was $450{ }^{\circ} \mathrm{C}$. The $\mathrm{GO} /$ ZnO-NR/GO composite showed better selectivity due to GO functional groups. In the case of our welldesigned sensors, we found that the dominant oxygen species $\left(\mathrm{O}^{2-}\right)$ on $\mathrm{ZnO}-\mathrm{NR}$ surface were responsible for the sensors response. These findings offer a new viewpoint for further advance of the sensing performance of one-dimensional $\mathrm{ZnO} / \mathrm{GO}$ nanocomposites VOCs sensors.
\end{abstract}

(C) 2016 Elsevier B.V. All rights reserved.

\section{Introduction}

$\mathrm{ZnO}$ is a semiconductor material extensively studied as a gas sensing material due to its good response to several gases, low cost, and facility for synthesizing nanostructures with different morphologies such as nanowires, nanorings, nanorods and others [1-5]. A variety of chemical and physical methods have been used to easily synthesize $\mathrm{ZnO}$ nanostructures such as chemical bath deposition [6], hydrothermal synthesis [7-10], microwave-assisted hydrothermal synthesis [11-13], among others.

The chemical bath deposition (CBD) is a technique that apart from being simple and economic allows synthesizing nanostructures with different morphologies at temperatures around $90{ }^{\circ} \mathrm{C}$ on various substrates $[14,15]$. The chemical bath can take place in aqueous solution where the mechanism leading to the formation of $\mathrm{ZnO}$ crystals involves the crystallization phenomenon,

\footnotetext{
* Corresponding author.

E-mail address: volanti@ibilce.unesp.br (D.P. Volanti).
}

dissolution, and recrystallization [16]. The chemical bath deposition is known to be similar to the hydrothermal synthesis though the former does not involve the use of atmospheric pressure.

Although many studies have been made to use $\mathrm{ZnO}$ nanorods and other nanostructures as sensor gas materials, problems related to poor stability and application of the sensor still exist [17-21]. On the other hand, graphene has been considered as a high applicable material, regarding excellent properties like high thermal stability and electrical conductivity, high mechanical performance and large surface area [22-24]. Due to simpler fabrication, the presence of functional groups on the surface and higher surface area, graphene oxide (GO) have been extensively studied to replace graphene as a gas sensor material [25].

In this context, composites based on graphene oxide and semiconductor nanostructures have emerged as a material to be used in gas sensor and other devices. This materials present higher surface area and additional functionalities once that functional groups in GO can act in favor of gas adsorption and synergistic effect between GO sheets and $\mathrm{ZnO}$ nanorods that can promote the 
electron transport [1,26-29].

Consequently, the use of such composites containing GO and $\mathrm{ZnO}$ can be an approach for volatile organic compounds (VOCs) detection. VOCs are known to be responsible for indoor pollution, resulting in adverse effects on human health [30,31]. The development of VOCs sensors with good stability, selectivity, sensibility toward low concentrations such as parts per million (ppm), and fast response is required for household security and environmental monitoring [32-34].

In this work, $\mathrm{ZnO}$ nanorods ( $\mathrm{ZnO}-\mathrm{NR}$ ) were grown on gold interdigital substrates at low temperatures by CBD. The composite $\mathrm{GO} / \mathrm{ZnO}-\mathrm{NR}$ was prepared by the same method, but now with GO sheets present as seeding layer in order to induce $\mathrm{ZnO}$ growth by the aid of the GO functional groups. Another proposed assembly type was $\mathrm{GO}$ deposition on the GO/ZnO-NR sample to obtain $\mathrm{GO} /$ $\mathrm{ZnO}-\mathrm{NR} / \mathrm{GO}$, and with better VOCs adsorption on the material surface. In addition, the vertical alignment of the one-dimensional (1D) ZnO-NR obtained by CBD method along with GO sheets improved the sensor active area for the selective VOCs adsorption. Finally, the easy process of the sensor fabrication with good sensing performance based on ZnO-NR structures/GO sheets has potential for application as acetone sensors and other VOCs.

\section{Experiment}

\subsection{Preparation of graphene oxide}

Expansible graphite was oxidized by modified Hummers' method. Pre-oxidizing reaction was carried out by adding $10 \mathrm{~g}$ of expansible graphite into an Erlenmeyer flask containing concentrated sulfuric acid, potassium persulfate and phosphorus pentoxide at $80{ }^{\circ} \mathrm{C}$. The reaction was allowed to be performed by the period of $6 \mathrm{~h}$, and the filler was washed until neutralization. The pre-oxidized graphite was submitted to a new oxidizing process in an Erlenmeyer flask containing concentrated sulfuric acid, sodium nitrate and potassium permanganate. The reaction was kept for the period of $2 \mathrm{~h}$, so, deionized water was added and the reaction was finished by the addition of hydrogen peroxide $30 \mathrm{vol} \%$. The solid was washed until the complete removal of manganese ions after the same was dispersed in deionized water and submitted to dialysis process in deionized water for about three weeks to remove residual ions. The aqueous suspension was submitted to ultrasonication before use it.

\subsection{Preparation of seeding layer}

For the seeding layer preparation, an ethanolic solution of $30 \mathrm{mmol} \mathrm{L}^{-1}$ of zinc acetate (ZnAc) or a $0.05 \mathrm{~g} \mathrm{~L}^{-1} \mathrm{GO}$ sheets solution was used. Such solutions were sprayed coated on the sensor substrate that consists of interdigitated comb-like Au electrodes on the front side of an alumina substrate by using a Spray Coating (Exacta Coat). The spray parameters used during deposition were $5 \mathrm{~W}, 1.00 \mathrm{KPa}, 0.30 \mathrm{~mL} \mathrm{~min}^{-1}$ and $100^{\circ} \mathrm{C}$. For preparation of seeding layer, two different kinds were prepared: (i) the seed layer consisting of only $\mathrm{ZnAc}$ layers prepared from $\mathrm{ZnAc}$ ethanolic solution sprayed 15 times on the substrate for ZnO-NR sample; (ii) the seed layer consisting of GO layers and ZnAc layer, where GO layers were obtained from GO solution sprayed 4 times followed by deposition of $\mathrm{ZnAc}$ ethanolic solution sprayed 12 times on the substrate for the $\mathrm{GO} / \mathrm{ZnO}-\mathrm{NR}$ and $\mathrm{GO} / \mathrm{ZnO}-\mathrm{NR} / \mathrm{GO}$ composites. After that, the samples were used for growing ZnO-NR by CBD.

\subsection{Preparation of the samples by chemical bath deposition}

The samples were synthesized on the bare sensor by CBD. In all syntheses, hexamethylenetetramine (HMTA, Aldrich) and zinc nitrate $\left(\mathrm{Zn}\left(\mathrm{NO}_{3}\right)_{2}\right.$, Aldrich) were mixed in the proportion $1: 1$ in a Polytetrafluoroethylene (PTFE) cup. For GO/ZnO-NR/GO synthesis, a $0.0125 \mathrm{~g} \mathrm{~L}^{-1} \mathrm{GO}$ solution was also added to the HMTA and $\mathrm{Zn}\left(\mathrm{NO}_{3}\right)_{2}$ in the PTFE vessel. After that, the sensor substrate was immersed in the precursor solution. The PTFE vessel was placed in silicone bath, and the solution was stirred and heated at $90{ }^{\circ} \mathrm{C}$ for $2 \mathrm{~h}$, aiming to promote the $\mathrm{ZnO}-\mathrm{NR}$ and $\mathrm{GO} / \mathrm{ZnO}-\mathrm{NR}$. Table 1 and Fig. 1 present an overview of the samples preparation.

\subsection{Characterization methods and VOCs sensing measurements}

The samples were characterized by Scanning Electron Microscopy (SEM) in a FEI Inspect F50 high-resolution SEM microscope with energy dispersive X-ray spectroscopy (EDX), and by Raman spectroscopy using a Confocal Raman model Horiba T64000 spectrometer with an exposure time of de $30 \mathrm{~s}$ and accumulation of 10 spectrums using a LASER source of $633 \mathrm{~nm}$.

For the VOCs sensing performance, the sensors were allocated inside the testing chamber $(754 \mathrm{~mL})$ and heated at the operating temperature, in the range of $200-500{ }^{\circ} \mathrm{C}$, under air flow of $250 \mathrm{~mL} \mathrm{~min}^{-1}$. The VOCs signal was measured by a high-voltage source-measure unit (Keithley Source meter 2400), applying a voltage of $5 \mathrm{~V}$. At the temperature of analysis the air flow was interrupted and the required time was used to stabilize the resistance of the sensors. Once the resistance was stable, the VOCs were inserted (10-500 ppm) by using a syringe, exposing the sensor to the VOC vapor for $50 \mathrm{~s}$. After the exposure time, the air flow of $250 \mathrm{~mL} \mathrm{~min}^{-1}$ was applied to clean the testing chamber from the VOC and to return to the initial state before the exposure. The response to reducing gases can be defined as the ratio $\left(R_{a} / R_{g}\right)$ of the resistance in air $\left(R_{a}\right)$ and the resistance after the VOCs exposure $\left(\mathrm{R}_{\mathrm{g}}\right)$.

\section{Results and discussion}

\subsection{Structural characterization}

The morphologies of grown $\mathrm{ZnO}-\mathrm{NR}$ on $\mathrm{Al}_{2} \mathrm{O}_{3}$ substrate with interdigitated gold electrodes were studied by SEM (Fig. 2). According to scanning electron micrograph of ZnO-NR, Fig. 2( $a$ and $b$ ), it is possible to see that ZnO-NR were grown vertically arranged on the grain of alumina substrate and showed hexagonal shape. Fig. 2(f) shows a cross section of the ZnO-NR arrays, where it can be seen that the nanorods length was around $640 \mathrm{~nm}$. For GO/ZnO-NR sample, the presence of $\mathrm{GO}$ as seeding layer was favorable to obtain nanorods with a larger diameter, as it can be observed in Fig. 2(c). Moreover, the presence of GO as seeding layer aided the nanorods growth using fewer layers of ZnAc during the synthesis than pure ZnO-NR. It occurred because of the functional groups of GO that improved the sites for the $\mathrm{ZnO}$ nanorods growth. Observing the micrographs of $\mathrm{GO} / \mathrm{ZnO}-\mathrm{NR} / \mathrm{GO}$ (Fig. 2(d and e)), it is clearly observed that the presence of GO solution also on $\mathrm{CBD}$ resulted in a coverage of the surface of $\mathrm{ZnO}$ nanorods by GO sheets. According to Wang et al. [1], the formation of nanocomposites based on $\mathrm{ZnO}$ nanosheets and GO sheets can decrease the surface energy and

Table 1

The samples compositions and the respective precursors used in seed layer (SL) and chemical bath deposition (CBD) steps.

\begin{tabular}{lll}
\hline Sample & Seed layer $(\mathrm{SL})$ & $\mathrm{CBD}$ \\
\hline $\mathrm{ZnO}-\mathrm{NR}$ & $\mathrm{ZnAc}$ & $\mathrm{Zn}\left(\mathrm{NO}_{3}\right)_{2}+$ HMTA \\
$\mathrm{GO} / \mathrm{ZnO}-\mathrm{NR}$ & $\mathrm{ZnAc}+\mathrm{GO}$ & $\mathrm{Zn}\left(\mathrm{NO}_{3}\right)_{2}+\mathrm{HMTA}$ \\
$\mathrm{GO} / \mathrm{ZnO}-\mathrm{NR} / \mathrm{GO}$ & $\mathrm{ZnAc}+\mathrm{GO}$ & $\mathrm{Zn}\left(\mathrm{NO}_{3}\right)_{2}+\mathrm{HMTA}+\mathrm{GO}$ \\
\hline
\end{tabular}




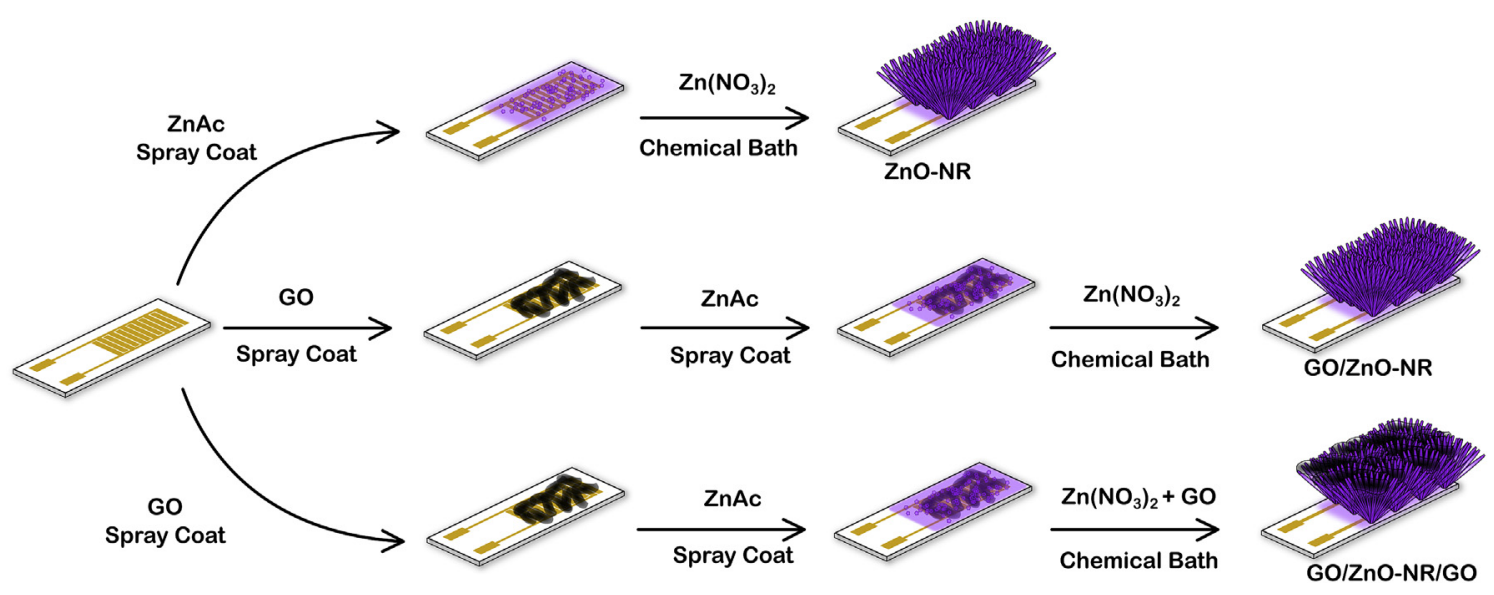

Fig. 1. Scheme of the preparation of $\mathrm{ZnO}-\mathrm{NR}, \mathrm{GO} / \mathrm{ZnO}-\mathrm{NR}$ and $\mathrm{GO} / \mathrm{ZnO}-\mathrm{NR} / \mathrm{GO}$ samples.

improve the stability of sensors. However, the $\mathrm{ZnO}-\mathrm{NR}$ density decreases for the $\mathrm{GO} / \mathrm{ZnO}-\mathrm{NR} / \mathrm{GO}$ because the growth of $\mathrm{ZnO}-\mathrm{NR}$ competes with the simultaneous deposition of the GO sheets during the synthesis.

The results of elemental compositions determined by EDX microanalysis are shown in Fig. 3 and Table 2. All the samples showed $\mathrm{Zn}$ and $\mathrm{O}$ elements in their composition referent to the presence of $\mathrm{ZnO}$ nanorods and $\mathrm{Al}$ element that is attributed to the substrate. Otherwise, the GO/ZnO-NR and GO/ZnO-NR/GO samples also showed $\mathrm{C}$ element in their composition that proves the presence of GO sheets. The quantity of $\mathrm{C}$ and $\mathrm{Al}$ element was higher for $\mathrm{GO} / \mathrm{ZnO}-\mathrm{NR} / \mathrm{GO}$ due to the presence of GO sheets on the $\mathrm{ZnO}$ nanorods surface and the lower ZnO-NR density (Fig. 2(d and e)).

Fig. 4(a) shows the Raman spectrum of GO sheets prepared by a modification of Hummers' method. The characteristics bands of graphene-based materials are observed, D band $\left(1300-1400 \mathrm{~cm}^{-1}\right)$ referent to double resonance Raman process, and the $G$ band $\left(1500-1700 \mathrm{~cm}^{-1}\right)$, which is related to first order transition with $\mathrm{E}_{2}$ g symmetry [35].

After growth of $\mathrm{ZnO}-\mathrm{NRs}$ by $\mathrm{CBD}$, the usual modes of $\mathrm{ZnO}$, such as $333 \mathrm{~cm}^{-1}$ (E $\mathrm{E}_{2}$ (high)- $\mathrm{E}_{2}$ (low) [36-38]), $437 \mathrm{~cm}^{-1}$ (E $\mathrm{E}_{2}$ (high) [39-41]) and $573 \mathrm{~cm}^{-1}\left(\mathrm{~A}_{1}(\mathrm{LO})\right.$ mode) are noticeably observed in the Raman spectra (Fig. 4(b)). The $\mathrm{E}_{2} 437 \mathrm{~cm}^{-1}$ peak is characteristic of the wurtzite lattice, and the $573 \mathrm{~cm}^{-1}$ band can be assigned to the electric field-induced (EFI) Raman scattering [40]. Besides of these peaks, it is also possible to verify the presence of the $D$ band and $G$ band referent to $G O$ in the samples prepared with the addition of $\mathrm{GO}(\mathrm{GO} / \mathrm{ZnO}-\mathrm{NR}$ and $\mathrm{GO} / \mathrm{ZnO} / \mathrm{GO})$. Though, the intensity of these bands is higher for the $\mathrm{GO} / \mathrm{ZnO}-\mathrm{NR} / \mathrm{GO}$ sample, where the GO sheets were previously identified on ZnO NRs surface by SEM (Fig. 2(d and e)). After the CBD process, it is observed for the sample $\mathrm{GO} / \mathrm{ZnO}-\mathrm{NR} / \mathrm{GO}$ that the $\mathrm{D}$ band possesses higher intensity in comparison with $\mathrm{G}$ band, this indicates that the carbon filler presents high structural peripheral defects content, which exhibits a higher intensity of D band due to the sheets packing [42].

\subsection{VOCs sensing properties}

The gas sensing measurements were performed at different temperatures to verify the optimum operating temperature to detect acetone. Fig. 5 displays the response to $200 \mathrm{ppm}$ of acetone at different temperatures, in the range of $200-500{ }^{\circ} \mathrm{C}$. The gas response of all sensors increased by increasing the temperature and achieved the maximum response at $450{ }^{\circ} \mathrm{C}$, and decreased with further increase of temperature. Furthermore, it is observed that at lower $\left(300-400{ }^{\circ} \mathrm{C}\right.$ ) temperatures, the $\mathrm{GO} / \mathrm{ZnO}-\mathrm{NR}$ and $\mathrm{GO} / \mathrm{ZnO}$ $\mathrm{NR} / \mathrm{GO}$ sensors showed an improved acetone performance in comparison with ZnO-NR. This behavior is attributed to GO functional groups presence in their composites. Thus, at the optimum operating temperature $\left(450^{\circ} \mathrm{C}\right)$, acetone response of $\mathrm{ZnO}-\mathrm{NR}, \mathrm{GO} /$ ZnO-NR and, GO/ZnO-NR/GO samples was found to be about 12.45 , 6.97, and 6.99, respectively.

Afterward, the gas measurements were carried out for $200 \mathrm{ppm}$ of different VOCs at $450{ }^{\circ} \mathrm{C}$ to study the selectivity of the sensors. As shown in Fig. 6, the response of all sensors toward acetone was higher than to ethanol, benzene, and methanol. However, one can see that the response of $\mathrm{GO} / \mathrm{ZnO}-\mathrm{NR}$ to acetone, benzene, ethanol and methanol was $6.97,1.97,6.46$ and 6.61 , respectively. This result demonstrated a poor selectivity of this sensor. On the other hand, the response of $\mathrm{ZnO}$-NR to acetone, benzene, ethanol and methanol was $12.52,1.37,11.38$ and 5.27 , and of the $\mathrm{GO} / \mathrm{ZnO}-\mathrm{NR} / \mathrm{GO}$ sensor was $6.99,1.27,5.96$ and 1.36 , in that order. In all cases, the response to benzene is poorer than to the other gases. Similar results have been previously reported, and this behavior may arise from the chemical bond of aromatic molecules [43]. It means that benzene activation and dissociation are difficult to achieve, and require the use of catalysts [44]. Moreover, VOCs such as ethanol present higher reactivity with the oxide surface [45]. Thus, our results indicate that $\mathrm{ZnO}-\mathrm{NR}$ and $\mathrm{GO} / \mathrm{ZnO}-\mathrm{NR} / \mathrm{GO}$ samples are more selective to acetone than $\mathrm{GO} / \mathrm{ZnO}-\mathrm{NR}$.

The sensing response of the sensors exposed to different concentrations of acetone ranging from 10 to $500 \mathrm{ppm}$ is shown in Fig. $7(\mathrm{a}-\mathrm{d})$. In all cases, the response increased with increasing acetone concentration and the capability of reversibility was noticed, which means that after acetone exposure the sensors could return to the initial state [46]. The gas response of the sensors as a function of acetone concentration is displayed in Fig. 7(d). It can be seen that the sensors based on GO/ZnO-NR and GO/ZnO-NR/GO exhibited the same performance to acetone detection. From 10 to $500 \mathrm{ppm}$, the responses of $\mathrm{GO} / \mathrm{ZnO}-\mathrm{NR}$ and $\mathrm{GO} / \mathrm{ZnO}-\mathrm{NR} / \mathrm{GO}$ changed from 2.40 to 10.67 and $1.92-10.06$, respectively. However, ZnO-NR showed a superior response than the other sensors for all acetone concentration. The response to $10 \mathrm{ppm}$ was 2.54 and to $500 \mathrm{ppm}$ was 19.51, which is almost twice higher than the value obtained for GO/ZnO-NR and GO/ZnO-NR/GO.

The response time consists of the time to reach $90 \%$ of the maximum signal of response after exposure to the gas. The response time for the samples was calculated. For GO/ZnO-NR, the response time ranged from $14.48 \mathrm{~s}$ for $10.77 \mathrm{~s}$ when the sample was exposed to $10-500 \mathrm{ppm}$ of acetone. For $\mathrm{ZnO}-\mathrm{NR}$, the response time 

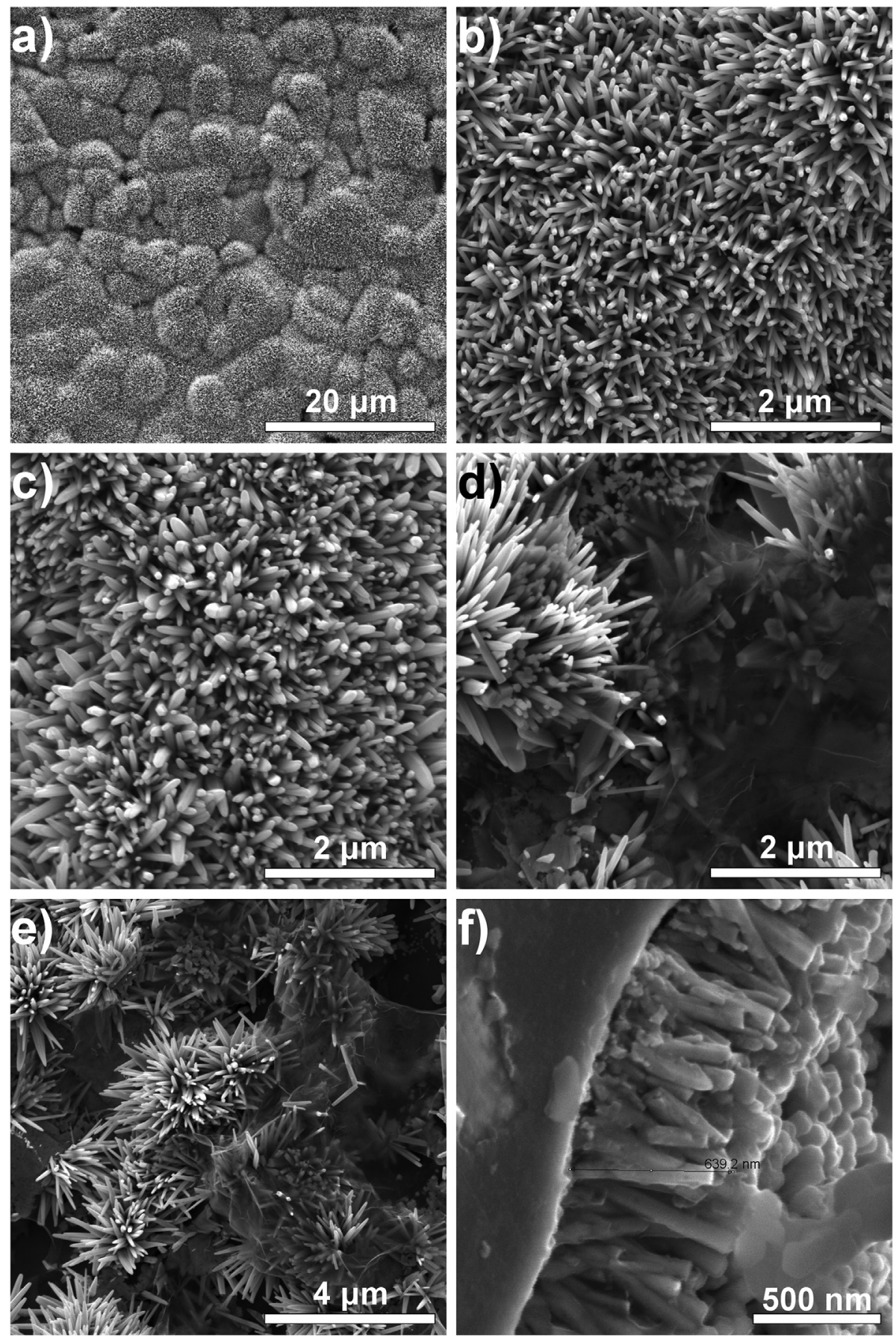

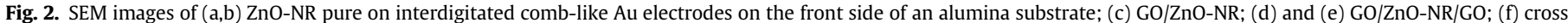
section of the ZnO-NR arrays.

ranged from $13.03 \mathrm{~s}$ for $6.35 \mathrm{~s}$ when the sample was exposed to $10-500 \mathrm{ppm}$ of acetone. For $\mathrm{GO} / \mathrm{ZnO}-\mathrm{NR} / \mathrm{GO}$, the response time ranged from $12.43 \mathrm{~s}$ for $8.79 \mathrm{~s}$ when the sample was exposed to 10-500 ppm of acetone.

The relationship between the gas concentration $\left(C_{g}\right)$ and the gas response $\left(\mathrm{S}_{\mathrm{g}}\right)$ can be written according to the gas absorption model of semiconductors as follows (Eq. (1)) [47,48]:

$S_{\mathrm{g}}=1+a C_{\mathrm{g}}^{\beta}$

Where $a$ is the prefactor and $\beta$ represents the response order, which gives information about the species charge on the surface. When the value of $\beta$ is 1 , the oxygen species adsorbed on the metal oxide surface are $\mathrm{O}^{-}$, whereas when it is 0.5 , the adsorbed species are $\mathrm{O}^{2-}$ $[49,50]$. To calculate $\beta$, Eq. (1) can be rewritten as (Eq. (2)):

$\log \left(S_{g}-1\right)=\log a+\beta \log C_{g}$

The relationship between the $\log \left(S_{g}-1\right)$ and $\log \left(C_{g}\right)$ is presented in Fig. 8, where it can be seen a good linear relationship for all the three sensors. The values of $\beta$ were found to be $0.648,0.489$ and 0.584 of the sensors $\mathrm{ZnO}-\mathrm{NR}, \mathrm{GO} / \mathrm{ZnO}-\mathrm{NR}$, and GO/ZnO-NR/GO. For all the cases, $\beta$ is close to 0.5 which suggests that the dominant 

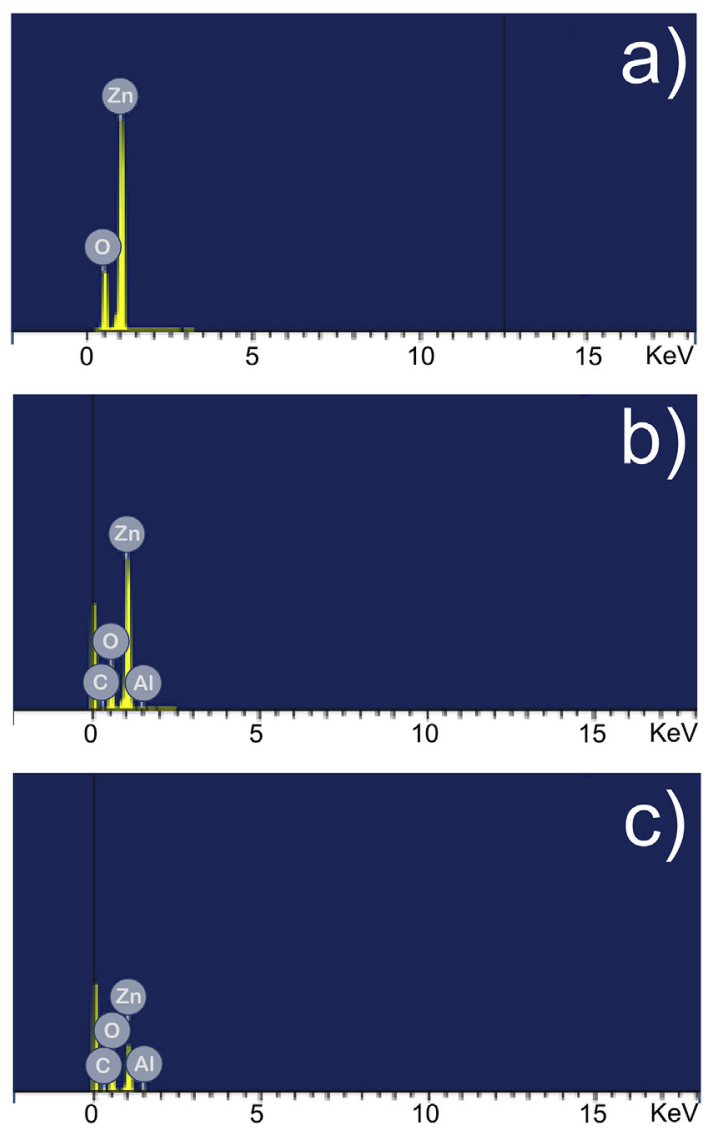

Fig. 3. EDX spectrum of (a) ZnO-NR, (b) GO/ZnO-NR, (c) GO/ZnO-NR/GO.

Table 2

Samples elemental compositions determined by EDX microanalysis.

\begin{tabular}{lllll}
\hline Sample & \multicolumn{4}{l}{ Elemental composition (weight \%) } \\
\cline { 2 - 5 } & Zn L & O K & C K & Al K \\
\hline ZnO-NR & 76.69 & 20.31 & 0.00 & 0.00 \\
GO/ZnO-NR & 77.04 & 20.60 & 1.96 & 0.4 \\
GO/ZnO-NR/GO & 74.22 & 20.66 & 3.85 & 1.27 \\
\hline
\end{tabular}

a)

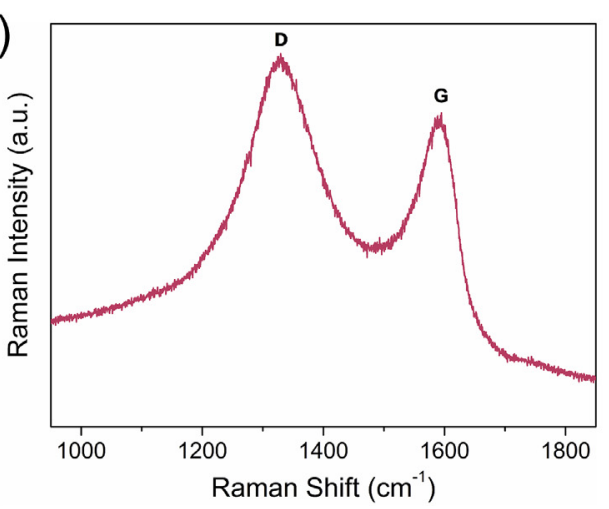

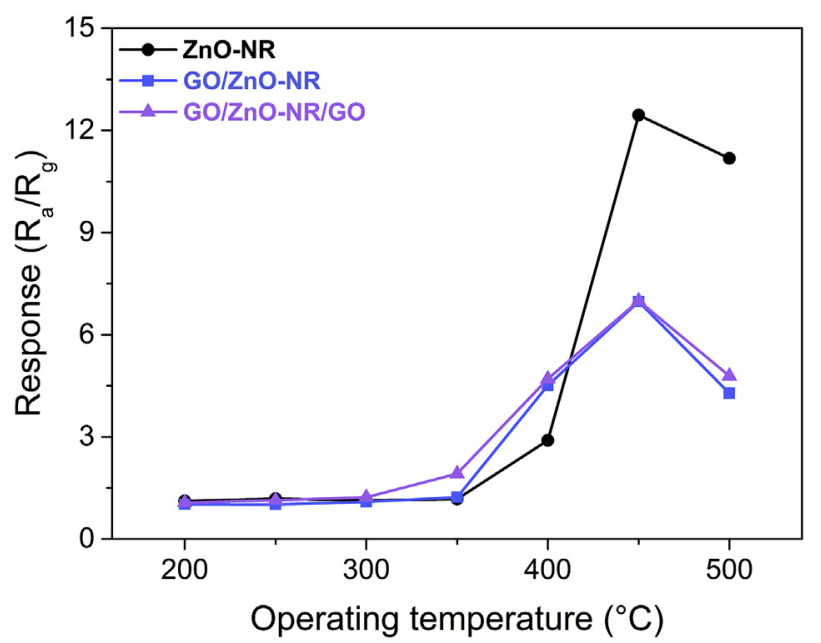

Fig. 5. Response of ZnO-NR, GO/ZnO-NR, and GO/ZnO-NR/GO samples to $200 \mathrm{ppm}$ of acetone at different operating temperatures $\left(200-500{ }^{\circ} \mathrm{C}\right)$.

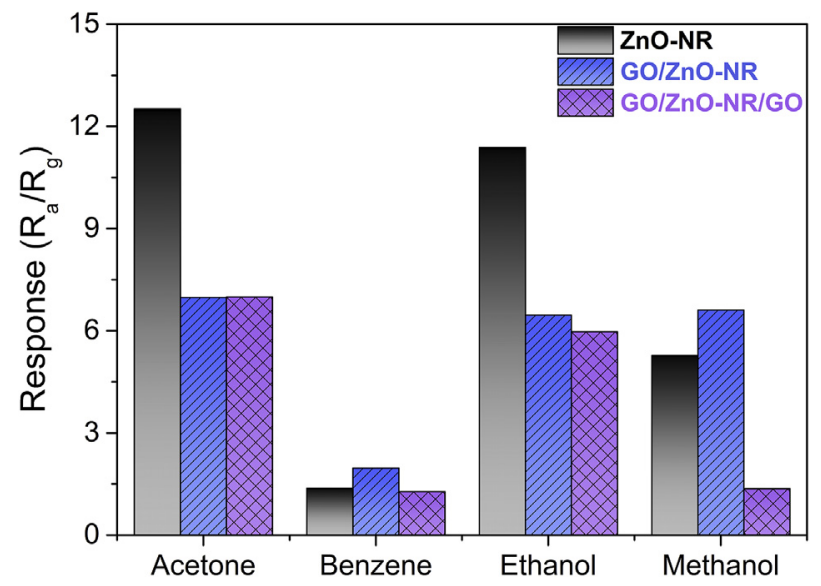

Fig. 6. Response of ZnO-NR, GO/ZnO-NR, and GO/ZnO-NR/GO to 200 ppm of different VOCs at $450^{\circ} \mathrm{C}$

Fig. 4. Raman spectra of: (a) GO sheets prepared by Hummers' Method and (b) ZnO-NR, GO/ZnO-NR and GO/ZnO-NR/GO.

adsorbed oxygen species on $\mathrm{ZnO}$ surface are $\mathrm{O}^{2-}$.

According to ionosorption model, atmospheric oxygen adsorbs on the surface of metal oxide semiconductors (MOS) and traps electrons from the conduction band. As a result, ionic species of b)

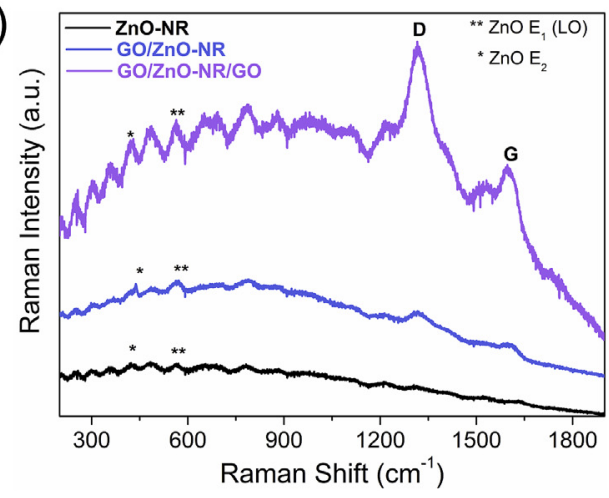


a)

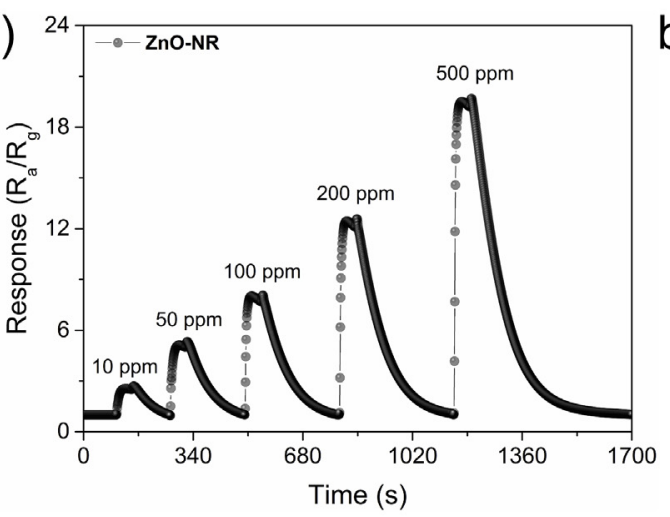

c)

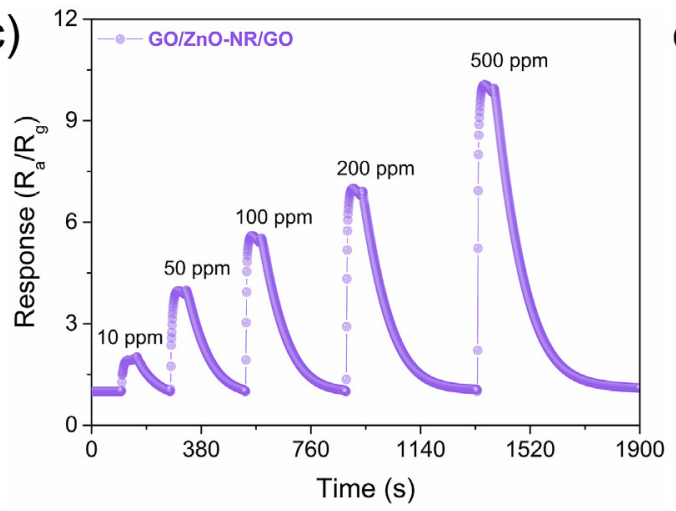

b)

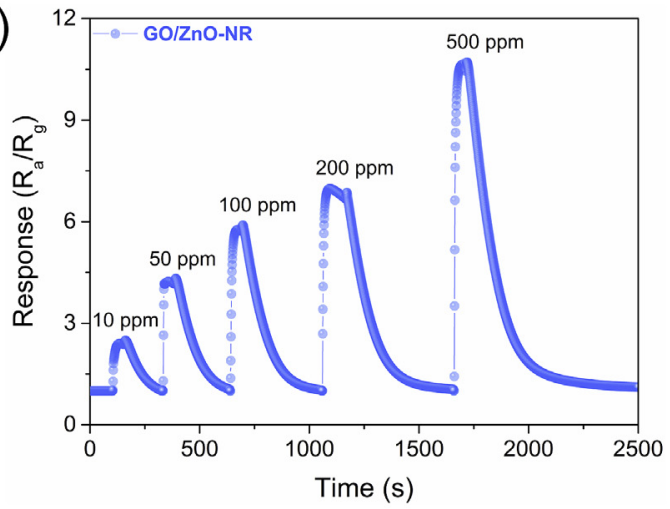

d)

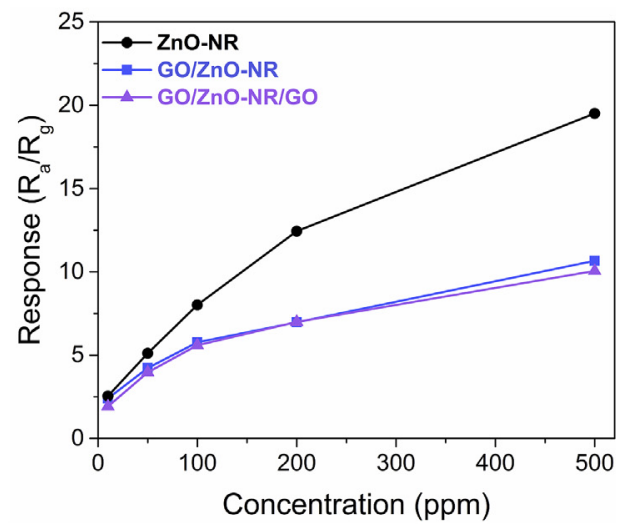

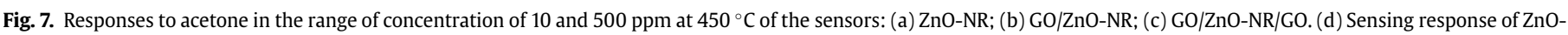
$\mathrm{NR}, \mathrm{GO} / \mathrm{ZnO}-\mathrm{NR}$, and $\mathrm{GO} / \mathrm{ZnO}-\mathrm{NR} / \mathrm{GO}$ as a function of acetone concentration.

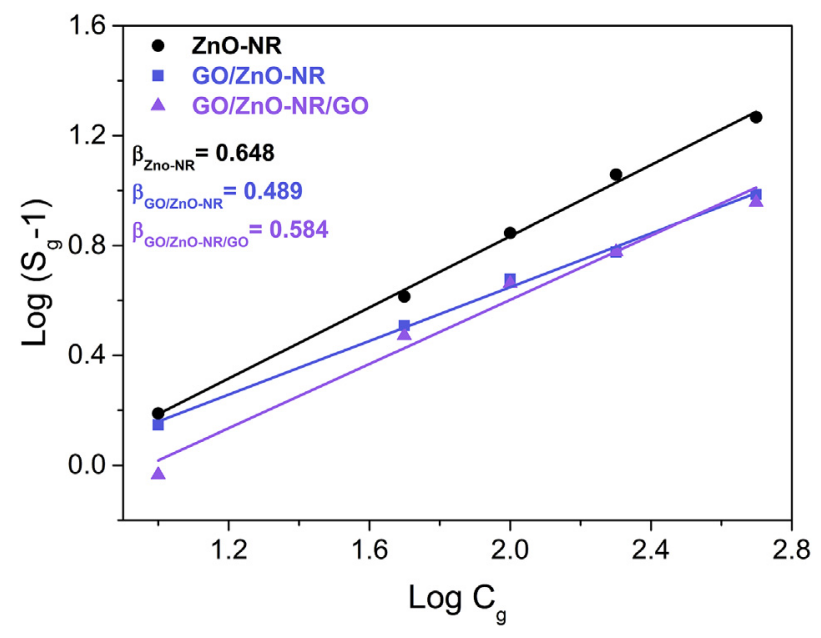

Fig. 8. $\log \left(\mathrm{S}_{\mathrm{g}}-1\right)$ in function of $\log \mathrm{C}_{\mathrm{g}}$ of the three sensors $(\mathrm{ZnO}-\mathrm{NR}, \mathrm{GO} / \mathrm{ZnO}-\mathrm{NR}$, and $\mathrm{GO} / \mathrm{ZnO}-\mathrm{NR} / \mathrm{GO})$.

$\mathrm{O}_{2(g)} \rightleftharpoons \mathrm{O}_{2(\text { ads })}$

$\mathrm{O}_{2(a d s)}+e^{-} \rightleftharpoons \mathrm{O}_{2(a d s)}^{-}$

$\mathrm{O}_{2(a d s)}^{-}+e^{-} \rightleftharpoons \mathrm{O}_{(a d s)}^{-}$

$\mathrm{O}_{(a d s)}^{-}+e^{-} \rightleftharpoons O_{(a d s)}^{2-}$
After the sensor is exposed to a reducing gas, such as acetone, the gas reacts with oxygen species on MOS surface and the trapped electrons are returned to the MOS, which promotes the decrease of electrical resistance. In the case of our sensors, we found that the dominant oxygen species on $\mathrm{ZnO}$ surface are $\mathrm{O}^{2-}$ as discussed above. Thus, the general reaction can be described as follows (Eq. (7)):

$$
\mathrm{CH}_{3} \mathrm{COCH}_{3(\mathrm{~g})}+8 \mathrm{O}_{(\mathrm{ads})}^{2-} \rightleftharpoons 3 \mathrm{CO}_{2(\mathrm{~g})}+3 \mathrm{H}_{2} \mathrm{O}_{(\mathrm{g})}+16 e^{-}
$$

Fig. 9 shows the proposed operating mechanism for the three kinds of sensors prepared in this work. Like this, for the $\mathrm{ZnO}$-NR structure, Fig. 9(a), the electron transfer in air atmosphere takes place according to the following reaction (Eq. (8)):

$2 \mathrm{O}^{2-}+\mathrm{O}_{2} \rightarrow \mathrm{V}_{\mathrm{O}}^{\mathrm{X}}$

When the temperature is increased to $450{ }^{\circ} \mathrm{C}$, to induce a stronger activation, more atomic oxygens are extracted from the surface, and consequently, more oxygen vacancies $\left(\mathrm{V}_{\mathrm{O}}^{\mathrm{X}}\right)$ are generated [47]. Therefore, reducing molecules as acetone react with the $\mathrm{O}^{2-}$ species present on the nanorods surface resulting in $\mathrm{CO}_{2}, \mathrm{H}_{2} \mathrm{O}$, and more electrons. The depletion layer becomes thinner, and increases the electronic flow in the conductive bulk area, resulting in a decrease of sensor resistance. The resistance changes are measured by gold electrodes placed below the $\mathrm{ZnO}-\mathrm{NR}$. A similar mechanism occurs in the GO/ZnO-NR and GO/ZnO-NR/GO nanocomposites (Fig. 9(b and c)). However, the presence of the GO between the ZnO-NR and the gold electrode resulted in a decrease of electronic flow. That behavior occurs because GO sheets contain saturated carbon atoms with $\mathrm{sp}^{3}$ hybridization that act as insulation [52]. Thus, it was noticed a lower acetone response for GO/ 
a)

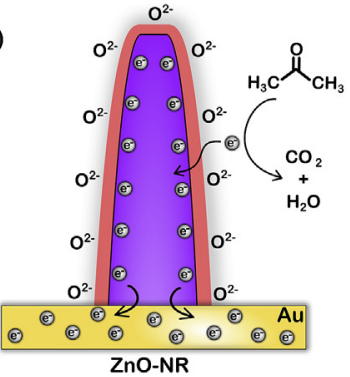

b)

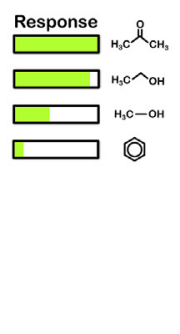

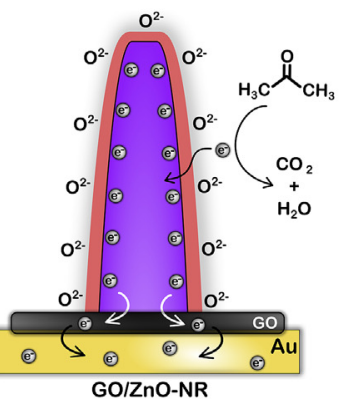

c)

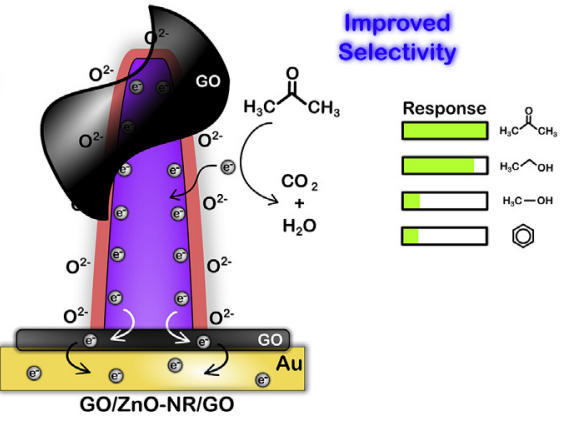

Fig. 9. Illustration of the VOCs sensing mechanism and selectivity of: (a) ZnO-NR, (b) GO/ZnO-NR, (c) GO/ZnO-NR/GO.

ZnO-NR and GO/ZnO-NR/GO than that of ZnO-NR at the optimum operating temperature. Moreover, for the GO/ZnO-NR/GO structure, Fig. 9(c), there is an improvement of the sensor selectivity. The deposited GO sheets on the $\mathrm{ZnO}-\mathrm{NR}$ increase the active area of the sensor, and the presence of the GO functional groups and structural defects work in selective interaction with acetone molecules.

\section{Conclusion}

The well-aligned $\mathrm{ZnO}$-NR grown on interdigital gold substrates by CBD is a good strategy to design new VOCs sensors. In addition, GO sheets deposited below the $\mathrm{ZnO}-\mathrm{NR}$ should affect the sensor resistance, reducing its responses to VOCs when compared to $\mathrm{ZnO}-$ NR sample. However, when a small amount of GO was placed above the nanorods, it could achieve better sensor selectivity. In this case, the GO functional groups promote gases adsorption on the sensor surface. Moreover, the dominant species $\left(\mathrm{O}^{2-}\right)$ present on the surface of the materials are responsible for the response of the sensors. The optimum working temperature of all sensors in the presence of $200 \mathrm{ppm}$ of acetone was $450^{\circ} \mathrm{C}$. Finally, the fine-tuning adjusting of zinc oxide/graphene composition and assembly sequence preparation is the critical key to the development of effective sensors.

\section{Acknowledgements}

The authors are thankful to São Paulo Research Foundation (FAPESP) (2014/17343-0, 2015/05916-9 and 2016/04371-1 grants), and The National Council for Scientific and Technological Development (CNPq) Proc. 444926/2014-3 by the financial support, and LME/LNNano/CNPEM and LMF/LNNano/CNPEM by the support in INSPECT F50 SEM analyses and bare sensor microfabrication, respectively. Contributions from Multiuser Laboratory of Advanced Optical Spectroscopy (LMEOA/IQ/UNICAMP) for the Raman facilities are also grateful.

\section{References}

[1] P. Wang, D. Wang, M. Zhang, Y. Zhu, Y. Xu, X. Ma, X. Wang, ZnO nanosheets/ graphene oxide nanocomposites for highly effective acetone vapor detection, Sens. Actuators B 230 (2016) 477-484, http://dx.doi.org/10.1016/ j.snb.2016.02.056.

[2] Q. Jia, H. Ji, Y. Zhang, Y. Chen, X. Sun, Z. Jin, Rapid and selective detection of acetone using hierarchical $\mathrm{ZnO}$ gas sensor for hazardous odor markers application, J. Hazard. Mater. 276 (2014) 262-270, http://dx.doi.org/10.1016/ j.jhazmat.2014.05.044.

[3] Y. Zeng, T. Zhang, M. Yuan, M. Kang, G. Lu, R. Wang, H. Fan, Y. He, H. Yang, Growth and selective acetone detection based on $\mathrm{ZnO}$ nanorod arrays, Sens. Actuators B 143 (2009) 93-98, http://dx.doi.org/10.1016/j.snb.2009.08.053.

[4] X. Yu, F. Song, B. Zhai, C. Zheng, Y. Wang, Electrospun ZnO nanotubes and its gas sensing applications, Physica E: low-Dimens, Syst. Nanostruct. 52 (2013) 92-96, http://dx.doi.org/10.1016/j.physe.2013.03.030.

[5] S. Wei, M. Zhou, W. Du, Improved acetone sensing properties of ZnO hollow nanofibers by single capillary electrospinning, Sens. Actuators B 160 (2011) 753-759, http://dx.doi.org/10.1016/j.snb.2011.08.059.

[6] M.E. Fragalà, Y. Aleeva, G. Malandrino, ZnO nanorod arrays fabrication via chemical bath deposition: ligand concentration effect study, Superlattices Microstruct. $48 \quad$ (2010) 408-415, http://dx.doi.org/10.1016/ j.spmi.2010.07.007.

[7] S. Ma, R. Li, C. Lv, W. Xu, X. Gou, Facile synthesis of $\mathrm{ZnO}$ nanorod arrays and hierarchical nanostructures for photocatalysis and gas sensor applications, J. Hazard. Mater. 192 (2011) 730-740, http://dx.doi.org/10.1016/ j.jhazmat.2011.05.082.

[8] Y. Cao, X. Hu, D. Wang, Y. Sun, P. Sun, J. Zheng, J. Ma, G. Lu, Flower-like hierarchical zinc oxide architectures: synthesis and gas sensing properties, Mater. Lett. 69 (2012) 45-47, http://dx.doi.org/10.1016/j.matlet.2011.11.037.

[9] J.X. Wang, X.W. Sun, Y. Yang, H. Huang, Y.C. Lee, O.K. Tan, L. Vayssieres, Hydrothermally grown oriented $\mathrm{ZnO}$ nanorod arrays for gas sensing applications, Nanotechnology 17 (2006) 4995-4998, http://dx.doi.org/10.1088/0957-4484/ $17 / 19 / 037$.

[10] J. Yu, B. Huang, X. Qin, X. Zhang, Z. Wang, H. Liu, Hydrothermal synthesis and characterization of ZnO films with different nanostructures, Appl. Surf. Sci. 257 (2011) 5563-5565, http://dx.doi.org/10.1016/j.apsusc.2011.01.039.

[11] P. Rai, H.-M. Song, Y.-S. Kim, M.-K. Song, P.-R. Oh, J.-M. Yoon, Y.-T. Yu, Microwave assisted hydrothermal synthesis of single crystalline $\mathrm{ZnO}$ nanorods for gas sensor application, Mater. Lett. 68 (2012) 90-93, http://dx.doi.org/ 10.1016/j.matlet.2011.10.029.

[12] X. Su, H. Zhao, F. Xiao, J. Jian, J. Wang, Synthesis of flower-like 3D ZnO microstructures and their size-dependent ethanol sensing properties, Ceram. Int. 38 (2012) 1643-1647, http://dx.doi.org/10.1016/j.ceramint.2011.09.055.

[13] N. Shojaee, T. Ebadzadeh, A. Aghaei, Effect of concentration and heating conditions on microwave-assisted hydrothermal synthesis of $\mathrm{ZnO}$ nanorods Mater. Charact. 61 (2010) 1418-1423, http://dx.doi.org/10.1016/ j.matchar.2010.08.006.

[14] T. Lee, H. Ryu, W.-J. Lee, Fast vertical growth of $\mathrm{ZnO}$ nanorods using a modified chemical bath deposition, J. Alloys Compd. 597 (2014) 85-90, http:// dx.doi.org/10.1016/j.jallcom.2014.02.003.

[15] S.V. Costa, A.S. Gonçalves, M.A. Zaguete, T. Mazon, A.F. Nogueira, ZnO nanostructures directly grown on paper and bacterial cellulose substrates without any surface modification layer, Chem. Commun. 49 (2013) 8096, http:// dx.doi.org/10.1039/c3cc43152e.

[16] S.L. Issler, C.C. Torardi, Solid state chemistry and luminescence of X-ray phosphors, J. Alloys Compd. 229 (1995) 54-65, http://dx.doi.org/10.1016/ 0925-8388(95)01686-4.

[17] Z. Wen, L. Zhu, Z. Zhang, Z. Ye, Fabrication of gas sensor based on mesoporous rhombus-shaped ZnO rod arrays, Sens. Actuators B 208 (2015) 112-121, http://dx.doi.org/10.1016/j.snb.2014.11.024.

[18] Y.-C. Liang, W.-K. Liao, X.-S. Deng, Synthesis and substantially enhanced gas sensing sensitivity of homogeneously nanoscale Pd- and Au-particle decorated ZnO nanostructures, J. Alloys Compd. 599 (2014) 87-92, http:// dx.doi.org/10.1016/j.jallcom.2014.01.167.

[19] J. Guo, J. Zhang, M. Zhu, D. Ju, H. Xu, B. Cao, High-performance gas sensor based on $\mathrm{ZnO}$ nanowires functionalized by Au nanoparticles, Sens. Actuators B 199 (2014) 339-345, http://dx.doi.org/10.1016/j.snb.2014.04.010.

[20] G. Gasparotto, T. Mazon, G. Gasparotto, M.A. Zaghete, L.A. Perazolli, J.A. Varela Gas sensor properties of $\mathrm{ZnO}$ nanorods grown by chemical bath deposition, Adv. Mater. Res. 975 (2014) 189-193, http://dx.doi.org/10.4028/www.scientific.net/AMR.975.189.

[21] L. Miao, H. Zhang, Y. Zhu, Y. Yang, O. Li, J. Li, Epitaxial growth of ZnO nanorods on electrospun $\mathrm{ZnO}$ nanofibers by hydrothermal method, J. Mater. Sci. Mater. Electron 23 (2012) 1887-1890, http://dx.doi.org/10.1007/s10854-012-06798.

[22] F. Schedin, A.K. Geim, S.V. Morozov, E.W. Hill, P. Blake, M.I. Katsnelson, K.S. Novoselov, Detection of individual gas molecules adsorbed on graphene, Nat. Mater. 6 (2007) 652-655, http://dx.doi.org/10.1038/nmat1967.

23] S. Stankovich, D.A. Dikin, R.D. Piner, K.A. Kohlhaas, A. Kleinhammes, Y. Jia, 
Y. Wu, S.T. Nguyen, R.S. Ruoff, Synthesis of graphene-based nanosheets via chemical reduction of exfoliated graphite oxide, Carbon 45 (2007) 1558-1565, http://dx.doi.org/10.1016/j.carbon.2007.02.034.

[24] X. Huang, X. Qi, F. Boey, H. Zhang, Graphene-based composites, Chem. Soc. Rev. 41 (2012) 666-686, http://dx.doi.org/10.1039/C1CS15078B.

[25] H.R. Hwang, J.G. Roh, D.D. Lee, J.O. Lim, J.S. Huh, Sensing behavior of the polypyrrole and polyaniline sensor for several volatile organic compounds, Met. Mater. Int. 9 (2003) 287-291, http://dx.doi.org/10.1007/BF03027048.

[26] D.-H. Yoo, T.V. Cuong, S. Lee, W.S. Hwang, W.J. Yoo, C.-H. Hong, S.H. Hahn, Unraveling oxygen transfer at the graphene oxide- $\mathrm{ZnO}$ nanorod interface, J. Phys. Chem. C 118 (2014) 17638-17642, http://dx.doi.org/10.1021/ jp5039046.

[27] J. He, C. Niu, C. Yang, J. Wang, X. Su, Reduced graphene oxide anchored with zinc oxide nanoparticles with enhanced photocatalytic activity and gas sensing properties, RSC Adv. 4 (2014) 60253-60259, http://dx.doi.org/ 10.1039/C4RA12707B.

[28] Y.-J. Kim, H. Yoo, C.-H. Lee, J.B. Park, H. Baek, M. Kim, G.-C. Yi, Position- and morphology-controlled $\mathrm{ZnO}$ nanostructures grown on graphene layers, Adv. Mater. 24 (2012) 5565-5569, http://dx.doi.org/10.1002/adma.201201966.

[29] Z. Yin, S. Wu, X. Zhou, X. Huang, O. Zhang, F. Boey, H. Zhang, Electrochemica deposition of $\mathrm{ZnO}$ nanorods on transparent reduced graphene oxide electrodes for hybrid solar cells, Small 6 (2010) 307-312, http://dx.doi.org/ 10.1002/smll.200901968.

[30] S. Wang, H.M. Ang, M.O. Tade, Volatile organic compounds in indoor environment and photocatalytic oxidation: state of the art, Environ. Int. 33 (2007) 694-705, http://dx.doi.org/10.1016/j.envint.2007.02.011.

[31] Y. Li, F. Li, C. Li, W. Wei, D. Jiang, L. Zhu, D. Sun, X. Zhang, S. Ruan, The preparation of $\mathrm{Cr}_{2} \mathrm{O}_{3} @ \mathrm{WO}_{3}$ hierarchical nanostructures and their application in the detection of volatile organic compounds (VOCs), RSC Adv. 5 (2015) 61528-61534, http://dx.doi.org/10.1039/C5RA06667K.

[32] H.-J. Kim, J.-H. Lee, Highly sensitive and selective gas sensors using p-type oxide semiconductors: overview, Sens. Actuators B 192 (2014) 607-627, http://dx.doi.org/10.1016/j.snb.2013.11.005.

[33] C. Wang X Cui, J. Liu, X. Zhou, X Cheng, P. Sun, X. Hu, X Li, J. Zheng G. Lu, Design of superior ethanol gas sensor based on Al-doped $\mathrm{NiO}$ nanorodflowers, ACS Sens. 1 (2015) 131-136, http://dx.doi.org/10.1021/ acssensors.5b00123.

[34] Y. Chang, Y. Yao, B. Wang, H. Luo, T. Li, L. Zhi, Reduced graphene oxide mediated $\mathrm{SnO}_{2}$ nanocrystals for enhanced gas-sensing properties, J. Mater. Sci. Technol. 29 (2013) 157-160, http://dx.doi.org/10.1016/j.jmst.2012.11.007.

[35] A.O. Lobo, A.A. Martin, E.F. Antunes, V.J. Trava-Airoldi, E.J. Corat Caracterização de materiais carbonosos por espectroscopia Raman, Rev. Bras. Apl. VÁcuo 24 (2005) 98-103, http://dx.doi.org/10.17563/rbav.v24i2.99.

[36] A. El Manouni, F.J. Manjón, M. Mollar, B. Marí, R. Gómez, M.C. López J.R. Ramos-Barrado, Effect of aluminium doping on zinc oxide thin films grown by spray pyrolysis, Superlattices Microstruct. 39 (2006) 185-192, http://dx.doi.org/10.1016/j.spmi.2005.08.041.

[37] S.L. Mensah, V.K. Kayastha, I.N. Ivanov, D.B. Geohegan, Y.K. Yap, Formation of single crystalline $\mathrm{ZnO}$ nanotubes without catalysts and templates, Appl. Phys. Lett. 90 (2007) 113108, http://dx.doi.org/10.1063/1.2714186.

[38] A. Umar, B. Karunagaran, E.-K. Suh, Y.B. Hahn, Structural and optical properties of single-crystalline $\mathrm{ZnO}$ nanorods grown on silicon by thermal evaporation, Nanotechnology 17 (2006) 4072-4077, http://dx.doi.org/ 10.1088/0957-4484/17/16/013.

[39] Y. Tak, D. Park, K. Yong, Characterization of ZnO nanorod arrays fabricated on Si wafers using a low-temperature synthesis method, J. Vac. Sci. Technol. B. Microelectron. Nanom. Struct. 24 (2006) 2047-2052, http://dx.doi.org/ 10.1116/1.2216714.

[40] M. Tzolov, N. Tzenov, D. Dimova-Malinovska, M. Kalitzova, C. Pizzuto, G. Vitali, G. Zollo, I. Ivanov, Vibrational properties and structure of undoped and Aldoped ZnO films deposited by RF magnetron sputtering, Thin Solid Films 379 (2000) 28-36, http://dx.doi.org/10.1016/S0040-6090(00)01413-9.

[41] K.A. Alim, V.A. Fonoberov, A.A. Balandin, Origin of the optical phonon frequency shifts in ZnO quantum dots, Appl. Phys. Lett. 86 (2005) 53103, http:// dx.doi.org/10.1063/1.1861509.

[42] K.N. Kudin, B. Ozbas, H.C. Schniepp, R.K. Prud'homme, I.A. Aksay, R. Car, Raman spectra of graphite oxide and functionalized graphene sheets, Nano Lett. 8 (2008) 36-41, http://dx.doi.org/10.1021/nl071822y.

[43] C. Ge, C. Xie, S. Cai, Preparation and gas-sensing properties of Ce-doped ZnO thin-film sensors by dip-coating, Mater. Sci. Eng. B 137 (2007) 53-58, http:// dx.doi.org/10.1016/j.mseb.2006.10.006.

[44] J. Hubálek, K. Malysz, J. Prášek, X. Vilanova, P. Ivanov, E. Llobet, J. Brezmes, $X$. Correig, Z. Sverrák, Pt-loaded $\mathrm{Al}_{2} \mathrm{O}_{3}$ catalytic filters for screen-printed $\mathrm{WO}_{3}$ sensors highly selective to benzene, Sens. Actuators B 101 (2004) 277-283, http://dx.doi.org/10.1016/j.snb.2004.01.015.

[45] Y.J. Hong, J.-W. Yoon, J.-H. Lee, Y.C. Kang, One-Pot synthesis of Pd-loaded $\mathrm{SnO}_{2}$ yolk-shell nanostructures for ultraselective methyl benzene sensors, Chem. A Eur. J. 20 (2014) 2737-2741, http://dx.doi.org/10.1002/chem.201304502.

[46] J.F. Fennell, S.F. Liu, J.M. Azzarelli, J.G. Weis, S. Rochat, K.A. Mirica J.B. Ravnsbaek, T.M. Swager, Nanowire chemical/biological sensors: status and a roadmap for the future, Angew. Chem. Int. Ed. Engl. 55 (2015) 1266-1281, http://dx.doi.org/10.1002/anie.201505308.

[47] Z. Wang, J. Xue, D. Han, F. Gu, Controllable defect redistribution of ZnO nanopyramids with exposed $\{10 \overline{11}\}$ facets for enhanced gas sensing performance, ACS Appl. Mater. Interfaces 7 (2015) 308-317, http://dx.doi.org/ 10.1021/am506206c.

[48] C. Wang, J. Liu, Q. Yang, P. Sun, Y. Gao, F. Liu, J. Zheng, G. Lu, Ultrasensitive and low detection limit of acetone gas sensor based on W-doped NiO hierarchical nanostructure, Sens. Actuators B 220 (2015) 59-67, http://dx.doi.org/ 10.1016/j.snb.2015.05.037.

[49] M.R. Alenezi, A.S. Alshammari, K.D.G.I. Jayawardena, M.J. Beliatis, S.J. Henley, S.R.P. Silva, Role of the exposed polar facets in the performance of thermally and UV activated ZnO nanostructured gas sensors, J. Phys. Chem. C 117 (2013) 17850-17858, http://dx.doi.org/10.1021/jp4061895.

[50] Y. Shi, M. Wang, C. Hong, Z. Yang, J. Deng, X. Song, L. Wang, J. Shao, H. Liu, Y. Ding, Multi-junction joints network self-assembled with converging $\mathrm{ZnO}$ nanowires as multi-barrier gas sensor, Sens. Actuators B 177 (2013) 1027-1034, http://dx.doi.org/10.1016/j.snb.2012.11.084.

[51] A. Gurlo, Interplay between $\mathrm{O}_{2}$ and $\mathrm{SnO}_{2}$ : oxygen ionosorption and spectroscopic evidence for adsorbed oxygen, ChemPhysChem 7 (2006) 2041-2052, http://dx.doi.org/10.1002/cphc.200600292.

[52] A. Bagri, C. Mattevi, M. Acik, Y.J. Chabal, M. Chhowalla, V.B. Shenoy, Structural evolution during the reduction of chemically derived graphene oxide, Nat. Chem. 2 (2010) 581-587. 